\title{
Prevalence, molecular epidemiology, and antimicrobial resistance of methicillin- resistant Staphylococcus aureus from swine in southern Italy
}

Mattia Pirolo ${ }^{1 \dagger}$, Angela Gioffrè ${ }^{2 \dagger}$, Daniela Visaggio ${ }^{1 \dagger}$, Monica Gherardi ${ }^{3}$, Grazia Pavia ${ }^{4}$, Pasquale Samele ${ }^{2}$, Lucia Ciambrone ${ }^{4}$, Rossella Di Natale ${ }^{5}$, Giovanna Spatari ${ }^{5}$, Francesco Casalinuovo ${ }^{4 \dagger}$ and Paolo Visca ${ }^{1 * \dagger}$ (D)

\begin{abstract}
Background: Colonization by livestock-associated MRSA (LA-MRSA) has increasingly been reported in the swine population worldwide. The aim of this study was to assess the prevalence of MRSA nasal carriage in healthy pigs, including the black (Calabrese) breed, from farms in the Calabria Region (Southern Italy). Between January and March 2018, a total of 475 healthy pigs reared in 32 farms were sampled by nasal swabbing. MRSA isolates were characterized by spa, MLST and SCCmec typing, and susceptibility testing to 17 antimicrobials.

Results: 22 of 32 (66.8\%) pig farms resulted positive for MRSA. The prevalence of MRSA was $46.1 \%$ (219 MRSA culture-positive out of 475 samples). MRSA colonization was significantly higher in intensive farms and in pigs with a recent or ongoing antimicrobial treatment. All 219 MRSA isolates were assigned to ST398. The most common spa types were t011 (37.0\%), t034 (22.4\%) and t899 (15.1\%). A novel spa type (t18290) was detected in one isolate. An insertion of IS256 in the ST398-specific A07 fragment of the SAPIG2195 gene was detected in 10 out of 81 t011 isolates. Nearly all isolates carried the SCCmec type $V$ element, except 11 isolates that carried the SCCmec type IVc. None of the isolates was positive for the Panton-Valentine leukocidin. All isolates were resistant to tetracycline. High resistance rates were also found for clindamycin (93.1\%), trimethoprim/sulfamethoxazole (68.4\%), fluoroquinolones (47.9-65.3\%) and erythromycin (46.1\%). None of the isolates was resistant to vancomycin and fusidic acid. Overall, a multidrug resistant phenotype was observed in $88.6 \%$ of isolates.

Conclusions: We report a high prevalence of MRSA among healthy swine in Southern Italy farms, with higher isolation frequency associated with intensive farming. The epidemiological types identified in our study reflect those reported in other European countries. Our findings underscore the importance of monitoring the evolution of LA-MRSA in pig farms in order to implement control measures and reduce the risk of spread in the animal population.
\end{abstract}

Keywords: LA-MRSA, Pigs, Genotyping, Antimicrobial susceptibility, Southern Italy

\footnotetext{
* Correspondence: paolo.visca@uniroma3.it

Mattia Pirolo, Angela Gioffrè, Daniela Visaggio, Francesco Casalinuovo and

Paolo Visca are equally contributed

'Department of Science, Roma Tre University, Viale G. Marconi 446, 00146

Rome, Italy

Full list of author information is available at the end of the article
}

(c) The Author(s). 2019 Open Access This article is distributed under the terms of the Creative Commons Attribution 4.0 International License (http://creativecommons.org/licenses/by/4.0/), which permits unrestricted use, distribution, and reproduction in any medium, provided you give appropriate credit to the original author(s) and the source, provide a link to the Creative Commons license, and indicate if changes were made. The Creative Commons Public Domain Dedication waiver (http://creativecommons.org/publicdomain/zero/1.0/) applies to the data made available in this article, unless otherwise stated. 


\section{Background}

Antimicrobial resistance is a looming public health crisis that threatens the effective prevention and treatment of infectious diseases. The development of antimicrobial resistance is accelerated by the misuse and overuse of antibiotics in human and veterinary medicine, animal farming and in agricultural settings [1]. In the modern animal husbandry antimicrobials are employed in large quantities to treat and prevent bacterial diseases [2]. The World Health Organization has urged a ban on growth-promoting antibiotics in fatten farm animals [3], a practice already banned in European Union (EU) and United States [4]. Despite these precautions, antimicrobial resistance among bacterial pathogens in the animal husbandry is progressively increasing, contributing to the spread of multi-drug resistant (MDR) microorganism in the community [5].

Methicillin-resistant Staphylococcus aureus (MRSA) has for long time been considered a prototypic nosocomial pathogen, showing highest prevalence in healthcare-associated infections (HA-MRSA) [6]. This view has changed over the last decades, since MRSA has become increasingly frequent in community acquired infections (CA-MRSA) in healthy people [7]. Furthermore, the high prevalence of MRSA in both pets and livestock highlights animals as a worrisome reservoir of this pathogen $[8,9]$. Livestock-associated MRSA (LA-MRSA) is considered a serious concern for the risks of zoonotic transmission, not only to people with occupational livestock exposure $[10,11]$, but also to the community through the food chain [12]. The foremost common LA-MRSA worldwide is the sequence type (ST) 398 belonging to clonal complex (CC) 398 [13]. Although LA-MRSA ST398 has been isolated from different livestock animals (i.e. veal calves, poultry, horses) [14-16], the main reservoir for this clone are pigs [13]. After the first isolation from pigs in France [17], ST398 was increasingly detected throughout Europe, accounting for 92.5\% of the MRSA isolates from breeding or production holdings of $17 \mathrm{EU}$ Member States [18]. As a foreseeable consequence, a recent survey by the European Centre for Disease Prevention and Control (ECDC) reports an increased prevalence of LA-MRSA in humans between 2007 and 2013 (from 1.7 to 3.9\%; ref. [19]. Therefore, in line with the "One World, One Health" principles [20], an integrated multi-sectorial surveillance including both healthcare and veterinary sources, to systematically map potential reservoirs and epidemiological trajectories of MRSA, has become mandatory [19].

In Italy, national surveillance data on MRSA are available only for nosocomial infections, in which MRSA account for $33.9 \%$ of $S$. aureus isolates from invasive infections in 2017 [21]. In contrast, systematic veterinary surveillance of LA-MRSA has not yet been established.
However, some studies reported an extremely high prevalence (34.9-38.1\%) of LA-MRSA from pig holdings in Italy $[18,22]$. These percentages reflect those seen in other EU countries with high density of swine farming, such as Germany (50-52\%) [23, 24], Spain (46\%) [25] and Belgium (44\%) [26]. An estimated MRSA prevalence of $37.6 \%$ was recently reported in slaughtered pigs of two industrial abattoirs in Southern Italy [27].

Given the serious threat of zoonotic MRSA transmission and the high isolation rate of LA-MRSA from intensive pig farms in Italy, the aims of the present study were: (i) to assess the prevalence of MRSA among asymptomatic swine, including the autochthonous black (Calabrese) pig breed [28, 29], from farms located in the Calabria region (Southern Italy); (ii) to investigate differences in MRSA carriage between intensive and non-intensive farming; (iii) to determine the clonal profiles of pig-associated MRSA isolates; (iv) to investigate the antimicrobial resistance patterns and the staphylococcal chromosomal cassette mec (SCCmec) type of MRSA isolates.

\section{Results}

\section{Prevalence of pig-associated MRSA}

The nasal carriage of MRSA in healthy swine reared in 32 farms with different type of breeding (25 intensive; 7 non-intensive) in all provinces of Calabria region (Additional file 1: Figure S1) was estimated. The characteristics of selected farms are summarized in Table 1.

From January to March 2018, a total of 475 nasal swabs were obtained from pigs ( 2 to 29 sampled animals per farm). Sampling and processing procedures for $S$. aureus detection and MRSA isolation from nasal swabs are outlined in Additional file 2: Figure S2 (see also Materials and Methods for details).

All farms resulted positive for the presence of $S$. aureus, with an overall prevalence of $82.1 \%$ (95\% CI: 81.8-82.4\%; Table 2); among these, more than half (22 out of 32 farms) were also positive for the presence of MRSA, with a prevalence of $46.1 \%$ (95\% CI: 45.9-46.3\%). A total of 219 non-duplicate MRSA isolates were obtained (Table 2).

Regarding $S$. aureus colonization, no significant differences in detection frequency were observed between intensive and non-intensive farms, pig breed (black vs. other breeds), and antimicrobial treatment (untreated vs. treated) (Table 2). Conversely, MRSA isolation was significantly higher among intensive than non-intensive farms (53.8\% versus $1.4 \%, p>0.001$; Table 2). As a consequence, the black pig, which was almost exclusive reared in non-intensive farms (Table 1), showed significantly lower colonization by MRSA than other breeds (9.1\% versus $53.3 \%, p>0.001$; Table 2). Finally, the MRSA isolation rate was significantly higher in pigs with 
Table 1 Characteristics of pig farms

\begin{tabular}{|c|c|c|c|c|c|}
\hline $\begin{array}{l}\text { Farm } \\
\text { ID }\end{array}$ & Province & $\begin{array}{l}\text { Breeding } \\
\text { type }\end{array}$ & $\begin{array}{l}\text { No. of farmed } \\
\text { pigs }\end{array}$ & $\begin{array}{l}\text { No. of sampled pigs (including black } \\
\text { pigs) }\end{array}$ & $\begin{array}{l}\text { No. of antibiotic-treated among sampled } \\
\text { pigs }^{\mathrm{a}}\end{array}$ \\
\hline $01 C Z$ & Catanzaro & Intensive & 275 & $12(0)$ & 3 \\
\hline $02 C Z$ & Catanzaro & Intensive & 380 & $10(1)$ & 6 \\
\hline $03 C Z$ & Catanzaro & Intensive & 300 & $10(0)$ & 8 \\
\hline $04 C Z$ & Catanzaro & Intensive & 20 & $14(0)$ & 0 \\
\hline $05 \mathrm{CS}$ & Cosenza & Intensive & 3967 & $29(0)$ & 0 \\
\hline $06 \mathrm{CS}$ & Cosenza & $\begin{array}{l}\text { Non- } \\
\text { intensive }\end{array}$ & 60 & $6(6)$ & 0 \\
\hline 07KR & Crotone & Intensive & 2309 & $19(2)$ & 2 \\
\hline $08 \mathrm{CZ}$ & Catanzaro & Intensive & 1010 & $18(0)$ & 0 \\
\hline $09 C Z$ & Catanzaro & Intensive & 10 & $8(0)$ & 1 \\
\hline 10RC & $\begin{array}{l}\text { Reggio } \\
\text { Calabria }\end{array}$ & Intensive & 341 & $18(0)$ & 0 \\
\hline $11 R C$ & $\begin{array}{l}\text { Reggio } \\
\text { Calabria }\end{array}$ & Intensive & 158 & $13(0)$ & 13 \\
\hline $12 \mathrm{RC}$ & $\begin{array}{l}\text { Reggio } \\
\text { Calabria }\end{array}$ & $\begin{array}{l}\text { Non- } \\
\text { intensive }\end{array}$ & 99 & $10(10)$ & 0 \\
\hline $13 C Z$ & Catanzaro & Intensive & 50 & $15(0)$ & 0 \\
\hline $14 C Z$ & Catanzaro & Intensive & 20 & $12(0)$ & 0 \\
\hline $15 C Z$ & Catanzaro & Intensive & 120 & $15(0)$ & 0 \\
\hline $16 \mathrm{CS}$ & Cosenza & $\begin{array}{l}\text { Non- } \\
\text { intensive }\end{array}$ & 170 & $17(17)$ & 0 \\
\hline $17 C S$ & Cosenza & $\begin{array}{l}\text { Non- } \\
\text { intensive }\end{array}$ & 1207 & $11(11)$ & 0 \\
\hline $18 \mathrm{CS}$ & Cosenza & Intensive & 600 & $10(0)$ & 0 \\
\hline $19 R C$ & $\begin{array}{l}\text { Reggio } \\
\text { Calabria }\end{array}$ & Intensive & 124 & $20(0)$ & 0 \\
\hline 20RC & $\begin{array}{l}\text { Reggio } \\
\text { Calabria }\end{array}$ & $\begin{array}{l}\text { Non- } \\
\text { intensive }\end{array}$ & 150 & $15(15)$ & 0 \\
\hline $21 R C$ & $\begin{array}{l}\text { Reggio } \\
\text { Calabria }\end{array}$ & Intensive & 330 & $16(0)$ & 0 \\
\hline $22 C Z$ & Catanzaro & Intensive & 850 & $30(0)$ & 0 \\
\hline $23 C Z$ & Catanzaro & Intensive & 400 & $20(0)$ & 20 \\
\hline $24 K R$ & Crotone & Intensive & 144 & $20(0)$ & 0 \\
\hline $25 K R$ & Crotone & Intensive & 300 & $14(0)$ & 0 \\
\hline $26 \mathrm{~W}$ & Vibo Valentia & Intensive & 132 & $23(3)$ & 0 \\
\hline $27 \mathrm{~W}$ & Vibo Valentia & $\begin{array}{l}\text { Non- } \\
\text { intensive }\end{array}$ & 24 & $10(10)$ & 0 \\
\hline $28 \mathrm{~W}$ & Vibo Valentia & Intensive & 10 & $9(1)$ & 0 \\
\hline $29 R C$ & $\begin{array}{l}\text { Reggio } \\
\text { Calabria }\end{array}$ & Intensive & 765 & $20(0)$ & 7 \\
\hline $30 R C$ & $\begin{array}{l}\text { Reggio } \\
\text { Calabria }\end{array}$ & $\begin{array}{l}\text { Non- } \\
\text { intensive }\end{array}$ & 32 & $2(2)$ & 0 \\
\hline $31 R C$ & $\begin{array}{l}\text { Reggio } \\
\text { Calabria }\end{array}$ & Intensive & 1101 & $20(0)$ & 0 \\
\hline $32 R C$ & $\begin{array}{l}\text { Reggio } \\
\text { Calabria }\end{array}$ & Intensive & 50 & $9(0)$ & 0 \\
\hline
\end{tabular}

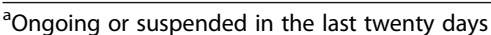


Table 2 Prevalence of S. aureus according to breeding type, breed and antimicrobial treatment

\begin{tabular}{|c|c|c|c|c|c|c|c|}
\hline \multirow[t]{2}{*}{ Variable } & \multirow[t]{2}{*}{ Category } & \multirow{2}{*}{$\begin{array}{l}\text { No. } \\
\text { of } \\
\text { farms }\end{array}$} & \multirow{2}{*}{$\begin{array}{l}\text { No. of } \\
\text { sampled } \\
\text { animals }\end{array}$} & \multicolumn{2}{|c|}{ S. aureus-positive } & \multicolumn{2}{|c|}{ MRSA-positive } \\
\hline & & & & No. (\%) & $P$-value & No. (\%) & $P$-value \\
\hline \multirow[t]{3}{*}{ Breeding type } & Intensive & 25 & 405 & $350(86.4)$ & NS & $218(53.8)$ & $>0.001$ \\
\hline & Non-intensive & 7 & 70 & $40(57.1)$ & & $1(1.4)$ & \\
\hline & Total & 32 & 475 & $390(82.1)$ & & $219(46.1)$ & \\
\hline \multirow[t]{3}{*}{ Breed } & Black pig & $11^{\mathrm{a}}$ & 77 & $47(61.0)$ & NS & $7(9.1)$ & $>0.001$ \\
\hline & Other breeds & 25 & 398 & $343(86.2)$ & & $212(53.3)$ & \\
\hline & Total & 32 & 475 & $390(82.1)$ & & $219(46.1)$ & \\
\hline \multirow[t]{3}{*}{ Antimicrobial treatment } & Treated $^{b}$ & - & 60 & $57(95.0)$ & NS & $45(75.0)$ & 0.010 \\
\hline & Untreated & - & 415 & $333(80.2)$ & & $174(41.9)$ & \\
\hline & Total & - & 475 & $390(82.1)$ & & $219(46.1)$ & \\
\hline
\end{tabular}

${ }^{\mathrm{a}} \mathrm{A}$ minority of black pigs were occasionally reared also in 4 intensive farms

${ }^{b}$ Ongoing or suspended in the last twenty days

NS, Not significant

an ongoing or recent antibiotic treatment (suspended in the last twenty days) than in untreated animals (75\% versus $41.9 \%, p=0.01$; Table 2 ).

\section{Clonal profiles of pig-associated MRSA isolates}

To determine the clonal profile of the pig-associated MRSA, spa typing, Multi Locus Sequence Typing (MLST) and SCCmec typing were performed. Thirteen different spa types were identified, and a minimum spanning tree was generated showing the type frequency and the genetic distance between types (Fig. 1a). The majority of isolates belonged to spa type t011 (81/219, 37.0\%), t034 (49/219, $22.4 \%)$ and t899 (33/219, 15.1\%). One new spa type, t18290, was detected in a black pig from a non-intensive farm (ID 06CS) (Fig. 1b). This new spa type is closely related to t011 since it differs by a single-nucleotide substitution in the third repeat (repeat 783 in t18290, instead of 02 in t011) (Additional file 3: Table S1). In 12 out of 22 (54.5\%) MRSA-positive farms, a single spa type was detected, whereas in the remaining 10 farms (45.5\%) two or more spa types were detected (Fig. 1b).

During our survey, a trade of pigs was documented between two farms, ID 07KR (seller) and 18CS (purchaser). Intriguingly, MRSA isolates from these two farms belonged to the t011 (18/18 in farm 07KR and 8/10 in 18CS; Fig. 1b).

The majority of spa types identified in this study have previously been associated to ST398. In order to verify this association, all isolates were screened by ST398-specific PCR [30]. This PCR generates an amplicon of $197 \mathrm{bp}$, corresponding to the fragment A07 of the SAPIG2195 gene (Gene ID: 12322222) [31]. As expected, an amplicon of $197 \mathrm{bp}$ was obtained for 209/219 MRSA isolates, suggesting that they belong to ST398. Of note, an amplicon of $1535 \mathrm{bp}$ was detected in 10/219 MRSA, all isolated from farm ID 05CS and belonging to t011 (Fig. 2a). DNA sequence analysis of the $1535 \mathrm{bp}$ amplicon revealed the presence of a $1329 \mathrm{bp}$ insertion in SAPIG2195. The inserted DNA displayed 99\% sequence identity with a genomic region of $S$. aureus WCH-SK2 (genome ID: CP031537; nucleotides 1,708,473-1,709,814) corresponding to IS256, including the $5^{\prime}$ and $3^{\prime}$ octanucleotide direct repeats (DR-L and DR-R) originated from the transposition event [32, 33]. The IS256 consists of a transposase gene (tnp) flanked by non-coding regions (NCR-L and NCR-R) that harbor $26 \mathrm{bp}$ imperfect inverted repeats (IR-L and IR-R) (Fig. 2b and Additional file 4: Figure S3).

To confirm that all the MRSA belonged to ST398, one MRSA isolate for each spa type was analysed by MLST, including one t011 strain that harboured the IS256 element in the SAPIG2195 gene. As expected, all MRSA isolates belonged to ST398, showing the allelic profile 335-19-2-20-26-39.

The vast majority (95.0\%) of MRSA isolates carried the SCCmec type V element, while few isolates, belonging to t899, carried SCCmec type IVc (5.0\%) (Additional file 3: Table S1). Finally, all the isolates were screened for the presence of the Panton-Valentine leucocidin (PVL) genes $(l u k S / l u k F)$. Of note, none of the MRSA isolates harboured the PVL genes.

\section{Antimicrobial susceptibility}

Antimicrobial susceptibility testing results on the 219 MRSA isolates are shown in Table 3. All isolates showed resistance to penicillin (PEN), oxacillin (OXA) and tetracycline (TET) and the majority of them was also resistant to clindamycin (CLI; 93.1\%), trimethoprim-sulfamethoxazole (SXT; 68.4\%), ampicillin/sulbactam (AMS; 66.2\%) and enrofloxacin (ENR; 65.3\%). Intriguingly, $48.9 \%$ of the MRSA isolates showed the lincosamide-resistant/macrolide-susceptible phenotype; more than half $(52.5 \%)$ of CLI-resistant isolates were susceptible to erythromycin 


\section{A}
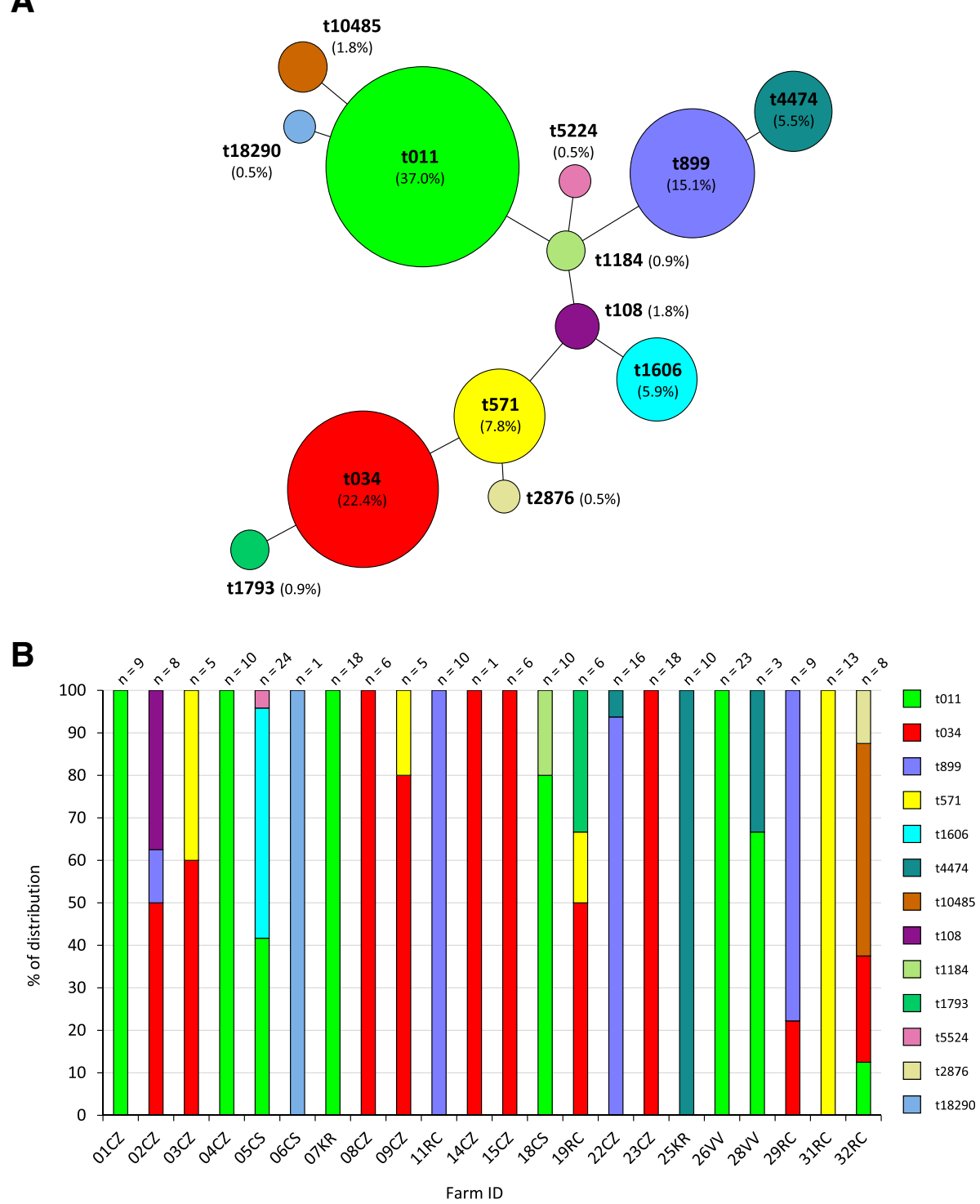

Fig. 1 Frequency and distribution of spa types for sampled farms. a Minimum spanning tree based on spa types for all MRSA isolates ( $n=219)$. Each node represents a different spa type. The diameter of node is proportional to the number of the isolates belonging to the spa type. $\mathbf{b}$ Distribution of spa types among 32 screened farms

(ERY). All the MRSA were susceptible to vancomycin (VAN) and fusidic acid (FUS) (Table 3). Nearly $90 \%$ of the MRSA isolates (213/219) were MDR, resulting resistant to at least three non $\beta$-lactams antimicrobial classes.

Overall, 77 resistance profiles were detected (Additional file 5: Table S2), with an antibiotype diversity of 0.54 (Additional file 6: Table S3). As a consequence, no correlation could be determined between the antibiotic resistance profile and spa or SCCmec type (Additional file 5: Table S2). The most frequent antibiotype, determined for $22 / 219$ (10.1\%) isolates, was OXA-PEN-AMS-ENR-marbofloxacin (MAR)-ERY-CLI-TET-SXT (Additional file 5: Table S2). The spa and SCCmec type distribution according to individual antimicrobial resistances is illustrated in Fig. 3 and details are provided in Additional file 6: Table S3.

\section{Discussion}

Following the European recommendations and given the high rate of MRSA isolation from livestock animals in EU, systematic monitoring and epidemiological characterization of circulating MRSA strains have become fundamental components of health and safety plans in many EU countries [34]. Our study represents the first systematic survey of MRSA carriage in swine within a defined region of Southern Italy. Calabria was chosen since it is a primary producer of several autochthonous pork products (e.g. 


\section{A}

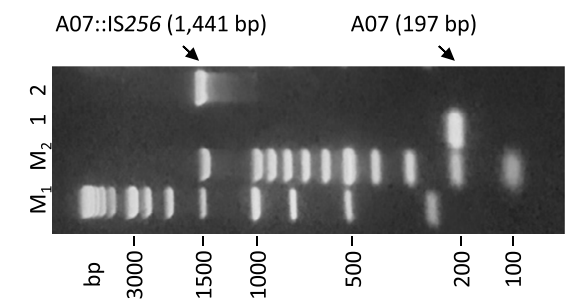

B

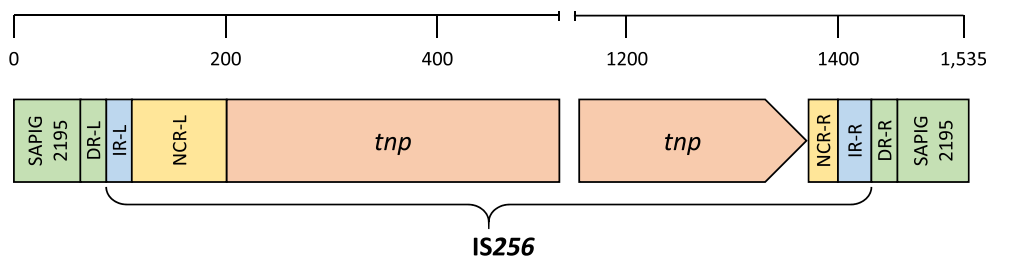

Fig. 2 IS256 insertion in the A07 fragment of the SAPIG2195 coding region. a ST398-specific PCR using primers A07f/A07r [30] of different t011 MRSA isolates from farm ID 05CS. Lanes 1 and 2, A07 (197 bp) and A07::IS256 (1535 bp), respectively. Lanes $\mathrm{M}_{1}$ and M2, 1 kb and 100 bp molecular size markers (Promega) respectively. b Schematic of the IS256 element inserted in the A07 fragment of SAPIG2195 [31]. The transposase gene (tnp) is flanked by non-coding regions (NCR-L and NCR-R) that harbor imperfect inverted repeats (IR-L and IR-R). The two octanucleotide direct repeats (DR-L and DR-R) flank the IS256

capocollo, pancetta, sausage, nduja), highly appreciated by the national and international market, and included in the list of Italian Protected Designation of Origin (PDO), as defined in the Council Regulation CE 510/2006. After sampling 475 pigs in 32 farms (Additional file 1: Figure S1; Table 1), the observed MRSA prevalence was $46.1 \%$, thus comparable with that reported for other Italian regions [27] and EU countries [23-26]. However, the MRSA prevalence was much higher in farms with an intensive type of breeding compared to non-intensive type (53.8\% versus $1.4 \%$, $p>0.001$ ) (Table 2). This finding is in accordance with previous reports demonstrating a strict correlation between the frequency of MRSA isolation and the crowded environment in the holdings [23, 25, 35-37], as opposed to organic farms (non-intensive holdings) in which the prevalence of LA-MRSA much lower [38, 39]. Accordingly, in our survey one out of 70 pigs reared in organic farms (1.4\%) was MRSA-positive (Table 2). This further corroborates the notion that the herd's management plays a key role in the containment of MRSA spreading. Moreover, the black (Calabrese) pig breed, which is one of the six Italian autochthonous pig breeds [28, 29], showed much lower

Table 3 Resistance to individual antimicrobials in 219 MRSA isolates from pigs

\begin{tabular}{|c|c|c|c|}
\hline Antimicrobial target & Antimicrobial class & Antimicrobial $^{a}$ & No. of non-susceptible $(R+I)$ isolates $(\%)^{b}$ \\
\hline \multirow[t]{5}{*}{ Peptidoglycan synthesis } & \multirow[t]{3}{*}{$\beta$-lactams } & PEN & $219(100)$ \\
\hline & & OXA & $219(100)$ \\
\hline & & AMS & $145(66.2)$ \\
\hline & Carbapenems & IMP & $22(10.0)$ \\
\hline & Glycopeptides & VAN & $0(0)$ \\
\hline \multirow[t]{2}{*}{ DNA synthesis } & \multirow[t]{2}{*}{ Fluoroquinolones } & ENR & $143(65.3)$ \\
\hline & & MAR & $105(47.9)$ \\
\hline \multirow[t]{8}{*}{ Protein synthesis } & \multirow[t]{2}{*}{ Aminoglycosides } & GEN & $43(19.6)$ \\
\hline & & KAN & $47(21.5)$ \\
\hline & Macrolides & ERY & $101(46.1)$ \\
\hline & Lincosamides & $C L I$ & $204(93.1)$ \\
\hline & Tetracyclines & TET & $219(100)$ \\
\hline & Fucidanes & FUS & $0(0)$ \\
\hline & Phenicols & CHL & $16(7.3)$ \\
\hline & Ansamycins & RIF & $1(0.5)$ \\
\hline \multirow[t]{2}{*}{ Others } & Nitrofuranes & NIT & $10(4.6)$ \\
\hline & Folate pathways inhibitors & SXT & $150(68.4)$ \\
\hline
\end{tabular}

acronyms: PEN, penicillin; OXA, oxacillin; AMS, ampicillin/sulbactam; IMP, imipenem; VAN; vancomicin; ENR, enrofloxacin; MAR, marbofloxacin; GEN, gentamycin; KAN, kanamycin; ERY, erythromycin; CLI, clindamycin; TET, tetracycline; FUS, fusidic acid; CHL, chloramphenicol; RIF, rifampicin; NIT, nitrofurantoin; SXT, trimethoprim-sulfamethoxazole

${ }^{\mathrm{b}}$ Isolates showing resistance $(\mathrm{R})$ and intermediate susceptibility (I) were classified as non-susceptible 


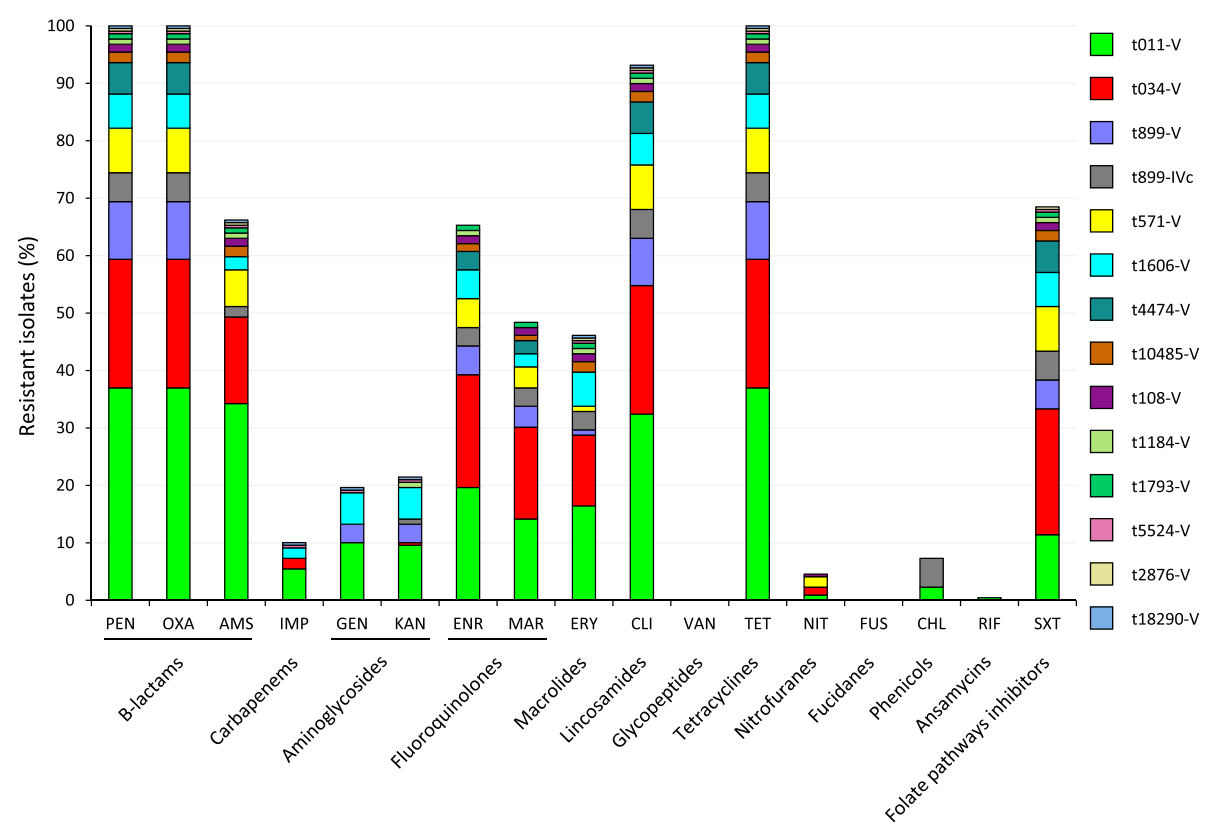

Fig. 3 Distribution of epidemiological types (combined spa and SCCmec type) according to the resistance to individual antimicrobial compounds

colonization rates compared with other breeds (9.1\% versus $53.3 \%, p>0.001$ ) (Table 2). This difference can be attributed to the fact that the black (Calabrese) pig is predominantly reared in non-intensive holdings, as opposed to the other breeds.

In EU countries, LA-MRSA isolates most often belong to ST (CC)398 [18], and are distributed in a large variety of spa types $[19,40]$. Accordingly, all 13 spa types identified in this study, including the new spa type t18290, belonged to ST398. Interestingly, in $54.5 \%$ of the farms, pigs were colonized with a single spa type, whereas in the remaining $45.4 \%$ the co-occurrence of two to four spa types was observed (Fig. 1b). Inter-farm trade of MRSA-positive swine can partly explain the occurrence of different spa types in the same holding. In fact, trade of animals between two holdings was documented in this study, and sampled animals from both farms were colonized with MRSA belonging to the same spa type (Fig. 1b).

In line with previous Italian studies [22, 27], the predominant spa types were t011, t034 and t899, accounting for $74.5 \%$ of all isolates (Fig. 1a). Interestingly, 10 isolates reared in the same farm (ID 05CS) and belonging to t011 were all characterized by the insertion of IS256 in the A07 fragment of the SAPIG2195 gene (Fig. 2). The IS256 is an insertion sequence that confers a strong genomic plasticity to MRSA [41]. Since IS256 is present in multiple copies in the staphylococcal genome [32], the dimension of the polymorphic inter-IS256 sequences has previously been used as a typing tool for MRSA [42]. This feature provides compelling evidence of the close genetic relatedness of this cluster of $\mathrm{t} 011$ isolates.
Regarding SCCmec element in our isolates, the most prevalent was type $\mathrm{V}$ (208 isolates, $95 \%$ ), which is frequently present in pig-associated ST398 MRSA [23, 40, 43]. The remaining 11 isolates (5\%), all belonging to t899, harboured the SCCmec type IVc (Additional file 3: Table S1), which is more common in CA-MRSA, as opposed to type IVa that prevails in LA-MRSA [44-46]. Moreover, the PVL genes were not detected in our collection of pig-associated MRSA, consistent with previous observations [22, 37, 47] and with the notion that PVL is a prevalent trait of CA-MRSA [48].

A typical feature of LA-MRSA is the ability to resist to several antimicrobials $[26,47,49]$. This has been ascribed to overuse and misuse of antibiotics in the animal husbandry, which drove the selection and evolution of resistance. The European Medicines Agency (EMA) and the European Surveillance of Veterinary Antimicrobial Consumption (ESVAC) reported a massive reduction of sales of veterinary antimicrobials in 24 out of 30 EU countries, including Italy (30\% reduction), between 2010 and 2016 [50]. Despite this policy, our survey highlights an overall high rate of antimicrobial resistance in pig-associated MRSA (Table 3), resulting $88.6 \%$ of isolates resistant to three or more classes of non $\beta$-lactams antimicrobials. Notably, MRSA prevalence was significantly higher in pigs with a recent or ongoing antimicrobial treatment, compared with untreated animals $(75 \%$ versus $41.9 \%, p=0.01$; Table 2 ), as also observed in other surveys $[23,35]$.

Seventy-seven different antimicrobial susceptibility profiles were identified among 219 LA-MRSA isolates 
(antibiotype diversity 0.54; Additional file 5: Table S2 and Additional file 6: Table S3), denoting extensive variability of antimicrobial resistance combinations within individual spa types. Tetracycline resistance is a hallmark of ST398 LA-MRSA from swine in Europe [22-25, 27, 37, 49], being the consequence of extensive usage of chlor- and oxy-tetracycline in pig farming [51]. This holds true also for lincosamides, macrolides and fluoroquinolones [52, 53]. Indeed, all our isolates were invariably resistant to TET, and showed high to medium frequency of resistance to CLI (93.1\%), ERY (46.1\%), ENR (65.3\%) and MAR (47.9\%) (Table 3). Of note, the atypical lincosamide-resistant/ macrolide-susceptible phenotype was observed for nearly half of the isolates. This resistance profile has increasingly been reported among ST398 MRSA from swine [54], and can be attributed to the spread of mobile genetic elements carrying the pleuromutilin-lincosamide-streptogramin A resistance genes (vga alleles) among swine-associated ST398 MRSA [55, 56]. A lower rate of gentamicin (GEN) and kanamycin (KAN) resistance (19.6 and 21.5\%, respectively) (Table 3) was observed, compared with previous reports from Italy (30\%; ref. [22] and other EU countries (35-45\%; refs. [23, 26, 40, 57]. Resistance to chloramphenicol (CHL), rifampicin (RIF), and FUS was infrequent or absent $(7.3,0.5$ and $0 \%$, respectively), as in previous surveys $[24,49,57-59]$.

SXT deserves a special comment. In the last years, an increase of SXT resistance in pig-associated MRSA has been documented, with percentages of resistance varying from 30 to $44 \%$ [23, 37, 59]. Here, we report an alarmingly high rate of SXT resistance (68.4\%), which in the future could further increase as a consequence of horizontal transmissibility of the $d f r K$ gene, encoding for trimethoprim-resistance [60]. Such high frequency of SXT resistance is probably due the selective pressure imposed by long-term exposure of animals to this drug, given that SXT is used as a metaphylactic (individual animal) or prophylactic (whole herd) preventive agent in intensive pig farming [61]. In our setting, however, such exposure cannot be proven, due to poor or incomplete information on antibiotic management available from farmers.

Remarkably, swine-associated MRSA from our study were invariably susceptible to VAN (Table 3), which remains the drug of choice for treatment of MRSA infections in humans [62].

\section{Conclusions}

The present study highlights the high prevalence of LA-MRSA ST398 among healthy pigs in intensive holdings in Southern Italy, as opposed to the low prevalence in non-intensive holdings. Circulating ST and spa types largely reflect the clonal distribution of LA-MRSA in the Italian and European pig farming industry. Susceptibility testing revealed extensive resistance to different classes of antimicrobials, especially those commonly used in pig husbandry. A worrisome increase in SXT resistance was observed, which deserves future attention. The high prevalence of ST398 LA-MRSA in intensive animal husbandry, together with its growing antimicrobial resistance, underscores the importance of monitoring the evolution of LA-MRSA in pig farms in order to implement control measures and reduce the risk of spread in the animal population.

\section{Methods}

\section{Study design and samples collection}

Between January and March 2018, a cross-sectional study was carried out in 32 swine herds located in all the five provinces of the Calabria region $\left(15,082 \mathrm{~km}^{2}\right)$ : Catanzaro (CZ; 11 farms), Reggio Calabria (RC; 10 farms), Cosenza (CS; 5 farms), Vibo Valentia (VV; 3 farms), Crotone (KR; 3 farms) (Additional file 1: Figure S1). Farms were selected by both geographic distribution and convenience, mainly based on the disposition of farmers to participate to the survey. The farms belonged to intensive (25/32) and non-intensive (7/32) types of breeding. Intensive-type farms were considered those in which animals were in crowded conditions. In these farms, swine were mainly represented by hybrids, deriving from crossings of different breeds (Large White, Durok, Danish and Polish). Swine holdings with non-intensive breeding systems were those in which animals were not confined between fences. In these farms, the autochthonous (Calabrese) black pig was the only reared breed.

Swab samples were collected from the nose of 475 animals, corresponding to 0.7 to $90 \%$ of the total swine livestock in each farm, depending on herd size (Table 1). Plastic swabs were pre-moistened in a sterile $0.9 \% \mathrm{NaCl}$ solution in order to increase the isolation rate of $S$. aureus, as previously documented [63]. Each swab was placed in a $15-\mathrm{ml}$ tube containing $5 \mathrm{ml}$ of Mueller Hinton Broth (MHB) (Becton Dickinson) supplemented with $6.5 \%(\mathrm{w} / \mathrm{vol})$ sodium chloride $(\mathrm{NaCl})$. Tubes were incubated for $24 \mathrm{~h}$ at $37^{\circ} \mathrm{C}$.

\section{Detection and isolation of $S$. aureus and MRSA}

All samples were processed according to a previously described protocol [64], with modifications (Additional file 2: Figure S2). Briefly, after 24-h swab incubation in $\mathrm{MHB}+6.5 \% \mathrm{NaCl}$ at $37^{\circ} \mathrm{C}, 0.5-\mathrm{ml}$ aliquots were transferred to $4.5 \mathrm{ml}$ of Phenol-Red Mannitol Broth (PRMB) (Becton Dickinson) and $4.5 \mathrm{ml}$ PRMB supplemented with $4 \mu \mathrm{g} / \mathrm{ml}$ of oxacillin (PRMB + OX). The two tubes, obtained from the same initial sample, were incubated for $24-48 \mathrm{~h}$ at $37^{\circ} \mathrm{C}$. If red-to-yellow colour change was observed in both samples (PRMB and PRMB + OX), $10-\mu \mathrm{l}$ from the culture with oxacillin (PRMB $+\mathrm{OX})$ were 
streaked on selective plates for MRSA (Brilliance MRSA 2 agar, Oxoid). Suspected MRSA colonies (blue coloured) were further streaked in Muller Hinton Agar (MHA) (Becton Dickinson) supplemented with $4 \mu \mathrm{g} / \mathrm{ml}$ of oxacillin for colony isolation. If only the tube with the PRMB culture changed the colour, $1 \mathrm{ml}$-aliquot was briefly centrifuged, and the pellet was tested for clumping factor, protein A and staphylococcal polysaccharides (Staphytect plus test, Oxoid) in order to confirm presumptive identification as $S$. aureus. The tubes that did not change colour after $48 \mathrm{~h}$ of incubation at $37^{\circ}$ $\mathrm{C}$ were considered negative for the presence of both S. aureus and MRSA. MRSA-negative samples were subjected to a second screening procedure (look-back) to exclude the presence of MRSA in the first enrichment medium $(\mathrm{MHB}+6.5 \% \mathrm{NaCl})$ (Additional file 2: Figure S2).

\section{Molecular typing}

Genomic DNA of the MRSA isolates was extracted by QIAamp DNA Mini Kit (QIAGEN) according to the manufacturer's recommendations, except for the addition of lysostaphin (Sigma Aldridch) at $50 \mu \mathrm{g} / \mathrm{ml}$ for the lysis step. S. aureus species identification and methicillin resistance were confirmed as previously described [65] by a multiplex PCR amplifying the genes $16 \mathrm{~S}$ rDNA, nuc and $m e c A$. The presence of $p v l$ genes (lukS-lukF) coding for the Panton-Valentine leukocidin (PVL) was tested as previously described [66].

The methods used for the genotyping the MRSA isolates were spa typing, MLST and SCCmec typing. The PCR to determine the spa type was performed as previously described [67]. Briefly, the polymorphic region of spa gene was amplified by PCR and the product was double-strand sequenced. The sequences (forward and reverse) were paired and analyzed with the spa typing plugin of the BioNumerics software version 6.6 (Applied Maths).

The ST398-specific PCR was carried out with primer sets A07f/A07r [30]. Analysis of the A07 fragment was performed by sequencing the amplicon with primers A07f/A07r.

MLST was performed using the method described by Enright et al. [68]. Seven housekeeping genes ( $\operatorname{arcC}$, aroE, $g l p F, g m k, p t a, t p i, y q i L)$ were amplified and sequenced on both DNA strands. The allelic profile and the ST were determined upon interrogation of the $S$. aureus MLST database of (http://saureus.mlst.net).

The SCCmec type was determined by a combination of multiplex PCR assays according to a previously described procedure $[69,70]$. The multiplex PCRs allow to discriminate the SCCmec element based on the amplicon size. Subtypes of the SCCmec type IV were determined as described by Milheirico et al. [71].

\section{Antimicrobial susceptibility testing}

Antimicrobial susceptibility was performed by Vitek2 system (bioMérieux), using the AST-P588 card for all strains. Strains were tested for susceptibility to $\beta$-lactams (PEN, OXA, AMS); carbapenems (imipenem; IMP); aminoglycosides (GEN, KAN); fluoroquinolones (ENR, MAR); macrolides (ERY); ansamycins (RIF); folate pathway inhibitors (SXT), fucidanes (FUS); lincosamides (CLI); glycopeptides (VAN); tetracyclines (TET); nitrofuranes (nitrofurantoin; NIT); phenicols (CHL). According to the CLSI interpretative criteria [72], MRSA isolates were classified as susceptible, intermediate, or resistant to each antibiotic. Strains classified as resistant and intermediate were included in the same group (non-susceptible).

\section{Statistical analysis}

Data analyses were performed using Sigma Plot software version 12.0 (Systat Software). Categorical variables were compared with the $X^{2}$ test or Fisher's exact test when appropriate. $P$ values of $\leq 0.05$ were considered statistically significant. Minimum-spanning-tree analysis of spa types was performed by using the BioNumerics software version 6.6 (Applied Maths).

\section{Additional files}

\section{Additional file 1: Figure S1 Geographic distribution of selected pig} farms in the Calabria region, Southern Italy. (PDF 285 kb)

Additional file 2: Figure S2 Flow-chart of S. aureus and MRSA screening procedure. (PDF $663 \mathrm{~kb}$ )

Additional file 3: Table S1 Distribution of SCCmec types according to the spa type. (PDF $12 \mathrm{~kb}$ )

Additional file 4: Figure S3 Sequence of the 1535-nt DNA amplicon containing the IS256 insertion in the A07 fragment of the SAPIG2195 coding region. (PDF $432 \mathrm{~kb}$ )

Additional file 5: Table S2 Antimicrobial resistance profile and epidemiological type of 219 MRSA isolates. (PDF $34 \mathrm{~kb}$ )

Additional file 6: Table S3 Diversity of antimicrobial susceptibility patterns among MRSA epidemiological types. (PDF $101 \mathrm{~kb}$ )

\section{Abbreviations}

AMS: Ampicillin/sulbactam; CA-MRSA: Community-associated methicillinresistant Staphylococcus aureus; CC: Clonal complex; CHL: Chloramphenicol; CS: Cosenza; CZ: Catanzaro; DR: Direct repeat; ECDC: European Centre for Disease Prevention and Control; EMA: European Medicines Agency; ENR: Enrofloxacin; ERY: Erythromycin; ESVAC: European Surveillance of Veterinary Antimicrobial Consumption; EU: European Union; FUS: Fusidic acid; GEN: Gentamicin; HA-MRSA: Healthcare-associated methicillin-resistant Staphylococcus aureus; IMP: Imipenem; IR: Inverted repeat; KAN: Kanamycin; KR: Crotone; LA-MRSA: Livestock-associated methicillin-resistant Staphylococcus aureus; MAR: Marbofloxacin; MDR: Multi-drug resistant; MHA: Muller Hinton Agar; MLST: Multi Locus Sequence Typing; MRSA: Methicillin-resistant Staphylococcus aureus; NCR: Non-coding region; NIT: Nitrofurantoin; OXA: Oxacillin; PDO: Protected Designation of Origin; PEN: Penicillin; PRMB: Phenol-Red Mannitol Broth; PVL: Panton-Valentine leucocidin; RC: Reggio Calabria; RIF: Rifampicin; SCCmec: Staphylococcal chromosomal cassette mec; ST: Sequence type; SXT: Trimethoprim-sulfamethoxazole; TET: Tetracycline; VAN: Vancomycin; W: Vibo Valentia 


\section{Acknowledgements}

The authors wish to thank D. Chiarelli, R. Fruci, P. Freccia, G. Galluzzo, S. Gentile, G. Principato, P. Rombolà, V. Rombolà, G. Talia and S. Virelli for their precious help during the sampling.

\section{Funding}

This work was supported by the grant BRIC ID 18/2016 from the Italian Workers' Compensation Authority (INAIL), and the grant of Excellence Departments, MIUR-Italy (Art. 1, commi 314-337 Legge 232/2016) to the Department of Science, Roma Tre University.

\section{Availability of data and materials}

All data generated or analysed during this study are included in this published article and its supplementary information files.

\section{Authors' contributions}

PV, FC, MG and DV conceived and designed the experiments. MP, AG, DV, GP and LC performed the experiments. MP, DV, AG, PS, GP, LC, RDN and FC analysed the data. MP, DV, FC and AG drafted the manuscript. MP, DV, AG, FC, GS and PV revised the manuscript. All authors read and approved the final manuscript.

\section{Ethics approval and consent to participate}

The authors declare that ethics approval and consent to participate do not apply to our study since nasal swab sampling is part of the routine animal surveillance protocols, issued by the National Authority for Veterinary Surveillance (Istituto Zooprofilattico Sperimentale del Mezzogiorno) under the control of the Italian Ministry of Health. In our study, surveillance was performed by a trained veterinary from the Istituto Zooprofilattico Sperimentale del Mezzogiorno, namely Dr. F. Casalinuovo, who co-authored the manuscript.

\section{Consent for publication}

Not applicable.

\section{Competing interests}

The authors declare that they have no competing interests.

\section{Publisher's Note}

Springer Nature remains neutral with regard to jurisdictional claims in published maps and institutional affiliations.

\section{Author details}

'Department of Science, Roma Tre University, Viale G. Marconi 446, 00146 Rome, Italy. ${ }^{2}$ Department of Medicine, Epidemiology, Workplace and Environmental Hygiene, Lamezia Terme Research Centre, INAIL - National Institute for Insurance against Accidents at Work, Lamezia Terme, Italy. ${ }^{3}$ Department of Medicine, Epidemiology, Workplace and Environmental Hygiene, Monte Porzio Catone Research Centre, INAIL - National Institute for Insurance against Accidents at Work, Rome, Italy. ${ }^{4}$ Istituto Zooprofilattico Sperimentale del Mezzogiorno, Catanzaro, Italy. ${ }^{5}$ Department of Biomedical Sciences, Dental, Morphological and Functional Investigations, University of Messina, Messina, Italy.

\section{Received: 14 December 2018 Accepted: 19 February 2019} Published online: 26 February 2019

\section{References}

1. Landers TF, Cohen B, Wittum TE, Larson EL. A review of antibiotic use in food animals: perspective, policy, and potential. Public Health Rep. 2012;127:4-22.

2. McEwen SA, Fedorka-Cray PJ. Antimicrobial Use and Resistance in Animals. Clin Infect Dis. 2002;34 Supplement 3:S93-106

3. Graham JP, Boland JJ, Silbergeld E. Growth promoting antibiotics in food animal production: an economic analysis. Public Health Rep. 2007:122:79-87.

4. Martin MJ, Thottathil SE, Newman TB. Antibiotics overuse in animal agriculture: a call to action for health care providers. Am J Public Health. 2015;105:2409-10

5. Tang KL, Caffrey NP, Nóbrega DB, Cork SC, Ronksley PE, Barkema HW, et al. Restricting the use of antibiotics in food-producing animals and its associations with antibiotic resistance in food-producing animals and human beings: a systematic review and meta-analysis. Lancet Planet Health. 2017;1:e316-27 Erratum in: Lancet Planet Health. 2017;1:e359.

6. Pantosti A, Venditti M. What is MRSA? Eur Respir J. 2009:34:1190-6.

7. Elston DM. Community-acquired methicillin-resistant Staphylococcus aureus. J Am Acad of Dermatol. 2007:56:1-16.

8. Loeffler A, Lloyd DH. Companion animals: a reservoir for methicillinresistant Staphylococcus aureus in the community? Epidemiol Infect. 2010;138:595-605.

9. Ballhausen B, Kriegeskorte A, van Alen S, Jung P, Köck R, Peters G, et al. The pathogenicity and host adaptation of livestock-associated MRSA CC398. Vet Microbiol. 2017;200:39-45.

10. Feßler AT, Olde Riekerink RGM, Rothkamp A, Kadlec K, Sampimon OC, Lam TJGM, et al. Characterization of methicillin-resistant Staphylococcus aureus CC398 obtained from humans and animals on dairy farms. Vet Microbiol. 2012;160:77-84

11. Köck R, Loth B, Köksal M, Schulte-Wülwer J, Harlizius J, Friedrich AW. Persistence of nasal colonization with livestock-associated methicillinresistant Staphylococcus aureus in pig farmers after holidays from pig exposure. Appl Environ Microbiol. 2012;78:4046-7.

12. Kluytmans JAJW. Methicillin-resistant Staphylococcus aureus in food products: cause for concern or case for complacency? Clin Microbiol Infect. 2010;16:11-5.

13. Smith TC, Pearson N. The emergence of Staphylococcus aureus ST398. Vector Borne Zoonotic Dis. 2010;11:327-39.

14. Graveland H, Wagenaar JA, Heesterbeek H, Mevius D, van Duijkeren E, Heederik D. Methicillin resistant Staphylococcus aureus ST398 in veal calf farming: human MRSA carriage related with animal antimicrobial usage and farm hygiene. PLoS One. 2010;5.

15. Monecke S, Ruppelt A, Wendlandt S, Schwarz S, Slickers P, Ehricht R, et al. Genotyping of Staphylococcus aureus isolates from diseased poultry. Vet Microbiol. 2013;162:806-12.

16. Guérin F, Fines-Guyon M, Meignen P, Delente G, Fondrinier C, Bourdon N, et al. Nationwide molecular epidemiology of methicillin-resistant Staphylococcus aureus responsible for horse infections in France. BMC Microbiol. 2017:17.

17. Armand-Lefevre L, Ruimy R, Andremont A. Clonal comparison of Staphylococcus aureus isolates from healthy pig farmers, human controls, and pigs. Emerg Infect Dis. 2005;11:711-4.

18. European Food Safety Authority (EFSA). Analysis of the baseline survey on the prevalence of methicillin-resistant Staphylococcus aureus (MRSA) in holdings with breeding pigs, in the EU, 2008 - part a: MRSA prevalence estimates: analysis of the baseline survey on MRSA in breeding pigs in the EU, 2008 - part a. EFSA J. 2009;7:1376

19. Kinross P, Petersen A, Skov R, Van Hauwermeiren E, Pantosti A, Laurent F, et al. Livestock-associated meticillin-resistant Staphylococcus aureus (MRSA) among human MRSA isolates, European Union/European economic area countries, 2013. Euro Surveill. 2017;22

20. van Helden PD, van Helden LS, Hoal EG. One world, one health. EMBO Rep. 2013;14:497-501.

21. European Centre for Disease Prevention and Control (ECDC). Surveillance of antimicrobial resistance in Europe - Annual report of the European Antimicrobial Resistance Surveillance Network (EARS-Net) 2017. Stockholm: ECDC; 2018.

22. Battisti A, Franco A, Merialdi G, Hasman $H$, lurescia M, Lorenzetti $R$, et al. Heterogeneity among methicillin-resistant Staphylococcus aureus from Italian pig finishing holdings. Vet Microbiol. 2010;142:361-6.

23. Alt K, Fetsch A, Schroeter A, Guerra B, Hammerl JA, Hertwig S, et al. Factors associated with the occurrence of MRSA CC398 in herds of fattening pigs in Germany. BMC Vet Res. 2011;7:69.

24. Mutters NT, Bieber CP, Hauck C, Reiner G, Malek V, Frank U. Comparison of livestock-associated and health care-associated MRSA-genes, virulence, and resistance. Diagn Microbiol Infect Dis. 2016;86:417-21.

25. Reynaga E, Navarro M, Vilamala A, Roure P, Quintana M, Garcia-Nuñez M, et al. Prevalence of colonization by methicillin-resistant Staphylococcus aureus ST398 in pigs and pig farm workers in an area of Catalonia, Spain. BMC Infect Dis. 2016;16:716.

26. Crombé $F$, Willems $G$, Dispas $M$, Hallin $M$, Denis $O$, Suetens $C$, et al. Prevalence and antimicrobial susceptibility of methicillin-resistant Staphylococcus aureus among pigs in Belgium. Microb Drug Resist. 2011;18:125-31. 
27. Normanno G, Dambrosio A, Lorusso V, Samoilis G, Di Taranto P, Parisi A. Methicillin-resistant Staphylococcus aureus (MRSA) in slaughtered pigs and abattoir workers in Italy. Food Microbiol. 2015;51:51-6.

28. Franci $\mathrm{O}$, Pugliese $\mathrm{C}$. Italian autochthonous pigs: progress report and research perspectives. Ital J Anim Sci. 2007;6:663-71.

29. Muñoz M, Bozzi R, García F, Núñez Y, Geraci C, Crovetti A, et al. Diversity across major and candidate genes in European local pig breeds. PLoS One. 2018;13:e0207475.

30. van Wamel WJB, Hansenová Maňásková S, Fluit AC, Verbrugh $H$, de Neeling

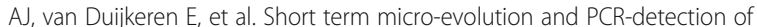
methicillin-resistant and -susceptible Staphylococcus aureus sequence type 398. Eur J Clin Microbiol Infect Dis. 2010;29:119-22.

31. Stegger M, Lindsay JA, Moodley A, Skov R, Broens EM, Guardabassi L. Rapid PCR detection of Staphylococcus aureus clonal complex 398 by targeting the restriction-modification system carrying sau1-hsdS1. J Clin Microbiol. 2011:49:732-4

32. Lyon BR, Gillespie MT, Skurray RA. Detection and characterization of IS256, an insertion sequence in Staphylococcus aureus. Microbiology. 1987;133:3031-8.

33. Byrne ME, Rouch DA, Skurray RA. Nucleotide sequence analysis of IS256 from the Staphylococcus aureus gentamicin-tobramycin-kanamycinresistance transposon Tn4001. Gene. 1989;81:361-7.

34. Joint scientific report of ECDC, EFSA and EMEA on meticillin resistant Staphylococcus aureus (MRSA) in livestock, companion animals and foods. EFSA-Q-2009-00612 (EFSA Scientific Report (2009) 301, 1-10) and EMEAVCVMP/ SAGAM/62464/2009. Available at https://www.ema.europa.eu/documents/ report/joint-scientific-report-european-centre-disease-prevention-controleuropean-food-safety-authority_en.pdf. (last accessed 21 Feb 2019).

35. van Duijkeren E, Ikawaty R, Broekhuizen-Stins MJ, Jansen MD, Spalburg EC, de Neeling AJ, et al. Transmission of methicillin-resistant Staphylococcus aureus strains between different kinds of pig farms. Vet Microbiol. 2008;126:383-9.

36. Fang H-W, Chiang P-H, Huang Y-C. Livestock-associated methicillin-resistant Staphylococcus aureus ST9 in pigs and related personnel in Taiwan. PLoS One. 2014;9:e88826.

37. Conceição T, de Lencastre $H$, Aires-de-Sousa M. Frequent isolation of methicillin resistant Staphylococcus aureus (MRSA) ST398 among healthy pigs in Portugal. PLoS One. 2017:12:e0175340.

38. Cuny C, Friedrich AW, Witte W. Absence of livestock-associated methicillinresistant Staphylococcus aureus clonal complex CC398 as a nasal colonizer of pigs raised in an alternative system. Appl Environ Microbiol. 2012;78:1296-7.

39. van de Vijver $L P L$, Tulinski $P$, Bondt N, Mevius D, Verwer C. Prevalence and molecular characteristics of methicillin-resistant Staphylococcus aureus (MRSA) in organic pig herds in the Netherlands. Zoonoses Public Health. 2014;61:338-45.

40. Peeters LEJ, Argudín MA, Azadikhah S, Butaye P. Antimicrobial resistance and population structure of Staphylococcus aureus recovered from pigs farms. Vet Microbiol. 2015;180:151-6.

41. Kleinert F, Kallies R, Hort M, Zweynert A, Szekat C, Nagel M, et al. Influence of IS256 on genome variability and formation of small-Colony variants in Staphylococcus aureus. Antimicrob Agents Chemother. 2017;61:e00144-17.

42. Deplano A, Vaneechoutte M, Verschraegen G, Struelens MJ. Typing of Staphylococcus aureus and Staphylococcus epidermidis strains by PCR analysis of inter-IS256 spacer length polymorphisms. J Clin Microbiol. 1997;35:2580-7.

43. Vanderhaeghen W, Hermans K, Haesebrouck F, Butaye P. Methicillin-resistant Staphylococcus aureus (MRSA) in food production animals. Epidemiol Infect. 2010;138:606-25.

44. Orendi JM, Coetzee N, Ellington MJ, Boakes E, Cookson BD, Hardy KJ, et al. Community and nosocomial transmission of Panton-valentine leucocidinpositive community-associated meticillin-resistant Staphylococcus aureus: implications for healthcare. J Hosp Infect. 2010;75:258-64.

45. Higashiyama M, Ito T, Han X, Nishiyama J, Tanno A, Wada T, et al. Trial to control an outbreak of Panton-valentine leukocidin-positive methicillinresistant Staphylococcus aureus at a boarding school in Japan. AJIC: Am J of Infect Control. 2011;39:858-65.

46. Butaye $P$, Argudín MA, Smith TC. Livestock-associated MRSA and its current evolution. Curr Clin Microbiol Rep. 2016;3:19-31.

47. Argudín MA, Tenhagen B-A, Fetsch A, Sachsenröder J, Käsbohrer A, Schroeter A, et al. Virulence and resistance determinants of German Staphylococcus aureus ST398 isolates from nonhuman sources. Appl Environ Microbiol. 2011;77:3052-60.
48. Saeed K, Gould I, Esposito S, Ahmad-Saeed N, Ahmed SS, Alp E, et al. Panton-valentine leukocidin-positive Staphylococcus aureus: a position statement from the international society of chemotherapy. Int J Antimicrob Agents. 2018:51:16-25.

49. Kadlec K, Ehricht R, Monecke S, Steinacker U, Kaspar H, Mankertz J, et al. Diversity of antimicrobial resistance pheno- and genotypes of methicillinresistant Staphylococcus aureus ST398 from diseased swine. J Antimicrob Chemother. 2009;64:1156-64.

50. European Medicines Agency (EMA), European Surveillance of Veterinary Antimicrobial Consumption (ESVAC), 2018. 'Sales of veterinary antimicrobial agents in 30 European countries in 2016'. (EMA/275982/2018).

51. Granados-Chinchilla F, Rodríguez C. Tetracyclines in food and Feedingstuffs: from regulation to analytical methods, bacterial resistance, and environmental and health implications. J Anal Methods Chem. 2017;2017.

52. Pyörälä S, Baptiste KE, Catry B, van Duijkeren E, Greko C, Moreno MA, et al. Macrolides and lincosamides in cattle and pigs: use and development of antimicrobial resistance. Vet J. 2014:200:230-9.

53. Hoeltig D, Rohde J, Brunner B, Hellmann K, Grandemange E, Waldmann K-H. Efficacy of a one-shot marbofloxacin treatment on acute pleuropneumonia after experimental aerosol inoculation of nursery pigs. Porcine Health Manag. 2018:4.

54. Pomba C, Baptista FM, Couto N, Loução F, Hasman H. Methicillin-resistant Staphylococcus aureus CC398 isolates with indistinguishable Apal restriction patterns in colonized and infected pigs and humans. J Antimicrob Chemother. 2010;65:2479-81.

55. Kadlec K, Pomba CF, Couto N, Schwarz S. Small plasmids carrying vga(a) or $\mathrm{vga}(\mathrm{C})$ genes mediate resistance to lincosamides, pleuromutilins and streptogramin a antibiotics in methicillin-resistant Staphylococcus aureus ST398 from swine. J Antimicrob Chemother. 2010;65:2692-3.

56. Schwendener S, Perreten V. New transposon Tn6133 in methicillin-resistant Staphylococcus aureus ST398 contains vga(E), a novel streptogramin a, pleuromutilin, and lincosamide resistance gene. Antimicrob Agents Chemother. 2011;55:4900-4.

57. de Neeling AJ, van den Broek MJM, Spalburg EC, van Santen-Verheuvel MG Dam-Deisz WDC, Boshuizen HC, et al. High prevalence of methicillin resistant Staphylococcus aureus in pigs. Vet Microbiol. 2007;122:366-72.

58. Zarfel G, Krziwanek K, Johler S, Hoenigl M, Leitner E, Kittinger C, et al. Virulence and antimicrobial resistance genes in human MRSA ST398 isolates in Austria. Epidemiol Infect. 2013;141:888-92.

59. Dierikx CM, Hengeveld PD, Veldman KT, de Haan A, van der Voorde S, Dop PY, et al. Ten years later: still a high prevalence of MRSA in slaughter pigs despite a significant reduction in antimicrobial usage in pigs the Netherlands. J Antimicrob Chemother. 2016:71:2414-8.

60. Kadlec K, Schwarz S. Identification of the novel dfrK-carrying transposon Tn559 in a porcine methicillin-susceptible Staphylococcus aureus ST398 strain. Antimicrob Agents Chemother. 2010;54:3475-7.

61. van Rennings $L$, von Münchhausen C, Ottilie H, Hartmann M, Merle R, Honscha W, et al. Cross-Sectional Study on Antibiotic Usage in Pigs in Germany. PLoS One. 2015;10:e0119114.

62. Liu C, Bayer A, Cosgrove SE, Daum RS, Fridkin SK, Gorwitz RJ, et al. Clinical practice guidelines by the Infectious Diseases Society of America for the treatment of methicillin-resistant Staphylococcus aureus infections in adults and children. Clin Infect Dis. 2011:52:e18-55.

63. Landers TF, Hoet A, Wittum TE. Swab type, moistening, and Preenrichment for Staphylococcus aureus on environmental surfaces. J Clin Microbiol. 2010; 48:2235-6.

64. Linhares LL, Yang M, Sreevatsan S, Munoz-Zanzi CA, Torremorell M, Davies PR. The effect of anatomic site and age on detection of Staphylococcus aureus in pigs. J Vet Diagn Investig. 2015;27:55-60.

65. Louie L, Goodfellow J, Mathieu P, Glatt A, Louie M, Simor AE. Rapid detection of methicillin-resistant staphylococci from blood culture bottles by using a multiplex PCR assay. J Clin Microbiol. 2002;40: 2786-90.

66. Lina G, Piémont Y, Godail-Gamot F, Bes M, Peter M-O, Gauduchon V et al. Involvement of Panton-valentine Leukocidin-producing Staphylococcus aureus in primary skin infections and pneumonia. Clin Infect Dis. 1999;29: 1128-32.

67. Harmsen D, Claus H, Witte W, Rothgänger J, Claus H, Turnwald D, et al. Typing of methicillin-resistant Staphylococcus aureus in a university hospital setting by using novel software for spa repeat determination and database management. J Clin Microbiol. 2003;41:5442-8. 
68. Enright MC, Day NPJ, Davies CE, Peacock SJ, Spratt BG. Multilocus sequence typing for characterization of methicillin-resistant and methicillin-susceptible clones of Staphylococcus aureus. J Clin Microbiol. 2000;38:1008-15.

69. Zhang K, McClure J-A, Elsayed S, Louie T, Conly JM. Novel multiplex PCR assay for characterization and concomitant subtyping of staphylococcal cassette chromosome mec types I to V in methicillin-resistant Staphylococcus aureus. J Clin Microbiol. 2005;43:5026-33.

70. Kondo Y, Ito T, Ma XX, Watanabe S, Kreiswirth BN, Etienne J, et al. Combination of multiplex PCRs for staphylococcal cassette chromosome mec type assignment: rapid identification system for $m e c, c c r$, and major differences in junkyard regions. Antimicrob Agents Chemother. 2007;51:264-74

71. Milheiriço C, Oliveira DC, de Lencastre H. Multiplex PCR strategy for subtyping the staphylococcal cassette chromosome mec type IV in methicillin-resistant Staphylococcus aureus: "SCCmec IV multiplex.". J Antimicrob Chemother. 2007;60:42-8.

72. Clinical and Laboratory Standards Institute. Methods for Dilution Antimicrobial Susceptibility Tests for Bacteria That Grow Aerobically. 10th ed. Wayne: CLSI (Approved standard M07-A10); 2015.

Ready to submit your research? Choose BMC and benefit from:

- fast, convenient online submission

- thorough peer review by experienced researchers in your field

- rapid publication on acceptance

- support for research data, including large and complex data types

- gold Open Access which fosters wider collaboration and increased citations

- maximum visibility for your research: over $100 \mathrm{M}$ website views per year

At BMC, research is always in progress.

Learn more biomedcentral.com/submissions 